\title{
Optimization of Machining Performance in High-Pressure Assisted Turning of Ti6Al4V Alloy
}

\author{
Oğuz Çolak* \\ Süleyman Demirel University, CAD/CAM Research and Application Center, Turkey
}

\begin{abstract}
In this study, a genetic algorithm has been employed to determine optimum cutting parameters in the turning of Ti6Al4V alloy under conventional and high pressure cooling conditions. Three machining performance measures, i.e. surface roughness, material removal rate and cutting power, are considered as optimization criteria. First, with multi-regression analysis of experimental responses, empirical equations are defined and, by using these equations, objective functions are constructed for each pressure level, based on a hybrid model. Objective functions are maximized by means of a genetic algorithm and optimum machining parameters are determined. Moreover, tool wear tests are carried out at a cutting condition that is close to the optimum machining parameters. Optimization results show that optimum cutting parameters and their responses, particularly in $P=6$ and 150 bar cooling conditions, are quite similar, but tool life is significantly different. Maximum tool life is achieved in the highest pressure level ( $P=300$ bar).
\end{abstract}

Keywords: high pressure cooling, optimization, tool life

\section{O INTRODUCTION}

Titanium alloys have found wide application in areas such as chemical processing equipment, surgical implants, and prosthetic devices, due to their excellent corrosion resistance, as well as in the automotive industry in engine components such as valves, connecting rods, drive shafts, crankshafts, and suspension assemblies, owing to their unique characteristics, including low density or high strengthto-weight ratio (density of titanium is about $60 \%$ of that of steel or nickel-based super alloys) [1] and [2].

They are considered to be difficult-to-machine materials due to the inherent material properties of high chemical reactivity and low thermal conductivity [3]. The major problems during machining are high temperatures and stresses close to the tool nose resulting in rapid tool wear. This is partly due to the poor thermal conductivity of titanium alloys, which implies that a considerable proportion of heat generated (about $80 \%$ ) during the machining process is conducted into the cutting tool [2] and [4].

Recently, various cooling-lubrication techniques have been developed to improve the machinability of titanium, nickel alloys and some other materials [5].

High-pressure jet-assisted cooling (HPJAC) is one of the main methods that aims to increase machining performance by using the thermal and mechanical properties of high-pressure jet water or emulsion injected into the cutting zone [6]. The application of a high-pressure water jet to the tool-chip interface during the machining of titanium, nickel alloys, in particular, which have superb properties has significant benefits in terms of machining performance, such as providing control of the chip shapes, better chip breakability, improved chip removal, considerably reduced temperatures in the cutting zone, resulting in prolonged tool life (5 to 15 times) [7] and [8]. It can also improve the surface integrity of workpieces [9]. Additionally, HPJAC enhances production efficiency compared to conventional cooling by increasing the cutting speed [10].

Çolak [6] studied the machinability of Inconel 718 under conventional and high pressure cooling conditions at various cutting speeds, feed rates, depths of cut, and pressure levels with a (Ti,Al) $\mathrm{N}+$ TiN-coated carbide cutting tool. He found that the injection of high-pressure coolant to the tool-chip interface reduces cutting force components, provides desirable chip breakability and lower cutting tool wear, especially flank face wear, due to the efficient lubrication and cooling than conventional cooling.

Palanisamy et al. [7] conducted an investigation on HPJAC in the turning of Ti6Al4V alloy. A series of experiments were carried out at various cutting parameters and pressure levels with uncoated straight tungsten carbide inserts. The investigation showed that the application of high-pressure directly on the tool-chip interface provides smaller chips due to the mechanical effect of high pressure, which generates a more efficient chip evacuation process. They also found that HPJAC increases tool life by almost three times in comparison to conventional cooling.

In many manufacturing industries, parameter setting is made based on the skill of the operator or on handbook recommendations. Consequently, optimum parameter setting is not achieved, which leads towards reduced production, poor quality and 
increased product costs [11]. Therefore, optimization of machining performance has great importance in terms of machining quality and cost for manufacturing industries.

Many studies in the literature have been performed on the optimization of machining operations and parameters by using various methods and models. Cus and Balic [12] conducted an investigation on cutting parameter optimization in milling by means of a genetic algorithm (GA) approach. The results of their proposed approach were compared with results of other approaches. They concluded that the GA approach can be integrated online with an intelligent manufacturing system for automated process planning; it can also use parameter selection of complex machined parts, which results in decreasing production cost, time and improving product quality. Raja and Baskar [13] studied machining parameters optimization to obtain the desired surface roughness in face milling by using a particle swarm optimization technique. The proposed approach reduces the time and cost of the trial for surface roughness prediction. It can also be utilized in industrial applications due to its predicting ability and accuracy. Da et al. [14] developed a hybrid model to optimize cutting parameters in turning by taking into account machining-performance factors, such as cutting force $\left(F_{c}\right)$, tool-life $(T)$, surface roughness $\left(R_{a}\right)$, material removal rate $\left(M_{R}\right)$ and chip breakability $(C B)$. Hagiwara et al. [15] also performed the same approach for the contour finish turning operations. Surface roughness and chip breakability were chosen as optimization criteria due to their significance to finish turning. They stated that optimum cutting parameters, determined via the GA approach, yielded better chip breakability and surface quality.

Several investigations that used the same approach can be found in the literature [16] to [18]. Furthermore, the present approach has been utilized in this research to determine optimum cutting parameters during the turning of Ti6Al4V under HPJAC and conventional cooling conditions based on three machining performances, i.e. the material removal rate $\left(M_{R}\right)$, cutting power $\left(P_{c}\right)$ and surface roughness $\left(R_{a}\right)$. Therefore, a number of machining tests with Ti6Al4V were carried out in conventional and various high pressure levels of cooling conditions. The experiments were designed based on a Taguchi L9 orthogonal array [23] at three different cutting speeds $\left(V_{c}\right)$, feed rates $(f)$ and pressure $(P)$ levels. Cutting forces $\left(F_{c}, F_{p}, F_{f}\right)$ and surface roughness $\left(R_{a}\right)$ were recorded during the experiments at a constant depth of cut $\left(a_{p}\right)$; moreover, the material removal rate
$\left(M_{R}\right)$ and cutting power $\left(P_{c}\right)$ were calculated according to cutting parameters and experimental responses. In order to construct objective functions for each pressure level, empirical equations that indicate the relation between cutting conditions and experimental responses were obtained via multi-regression analysis. Objective functions were maximized by means of GA, and optimum machining parameters were determined. Finally, tool wear tests were carried out at a cutting condition that is close to the optimum machining parameters.

\section{EXPERIMENTAL PROCEDURE}

The experiments were designed according to plan of a Taguchi L9 orthogonal array at three different cutting speeds, feed rates and pressure levels, and depths of cut were kept constant during the tests. Each experiment was performed with new cutting edge to compare results. Cutting parameters and their levels are given in Table 1.

Table 1. The levels of cutting parameters

\begin{tabular}{lccc}
\hline Level & I & II & III \\
\hline$V_{c}[\mathrm{~m} / \mathrm{min}]$ & 50 & 70 & 90 \\
\hline$f[\mathrm{~mm} / \mathrm{rev}]$ & 0.1 & 0.15 & 0.2 \\
\hline$P[\mathrm{bar}]$ & Conv. $(6)$ & 150 & 300 \\
\hline$a_{p}[\mathrm{~mm}]$ & 2 & - & - \\
\hline
\end{tabular}

The experiments were conducted on an ALEX ANL-75 CNC lathe machine that has a variable spindle speed (50 to $4000 \mathrm{rpm}$ ) and a $15 \mathrm{~kW}$ motor drive that is equipped with the high-pressure plunger pump of maximum 350 bar pressure and $21 \mathrm{l} / \mathrm{min}$ volumetric flow rate capacity (Fig. 1). The cutting fluid used in experiments was a chemical-based 6 to $7 \%$ concentration water soluble oil (Swisslube Blaser BCool 650). The high pressure cutting fluid was injected between the cutting tool-chip interface at a low angle (about 5 to $6^{\circ}$ with the cutting tool rake angle), as shown in Fig. 1.

A CNMG0812 (Ti,Al)N+TiN-coated carbide cutting tool has been chosen for the experiments. The tool has $r_{\varepsilon}=0.8 \mathrm{~mm}$ nose radius. It was mounted on a SECO Jet stream PCLNR tool holder, which resulted in: cutting rake angle, $\gamma_{a}=-6^{\circ}$, back rake angle, $\gamma_{b}=-6^{\circ}$, approach angle, $K_{r}=95^{\circ}$, and $d=0.8 \mathrm{~mm}$ nozzle diameter. All the experiments were carried out using the Ti6Al4V alloy supplied as bars $(80 \mathrm{~mm}$ diameter and $200 \mathrm{~mm}$ long) with a hardness of 292 do $407 \mathrm{HV}_{100}$. The standard chemical composition is $0.08 \% \mathrm{C}, 5.5$ to $6.75 \% \mathrm{Al}, 3.5$ to $4.5 \% \mathrm{~V}, 0.03 \%$ 


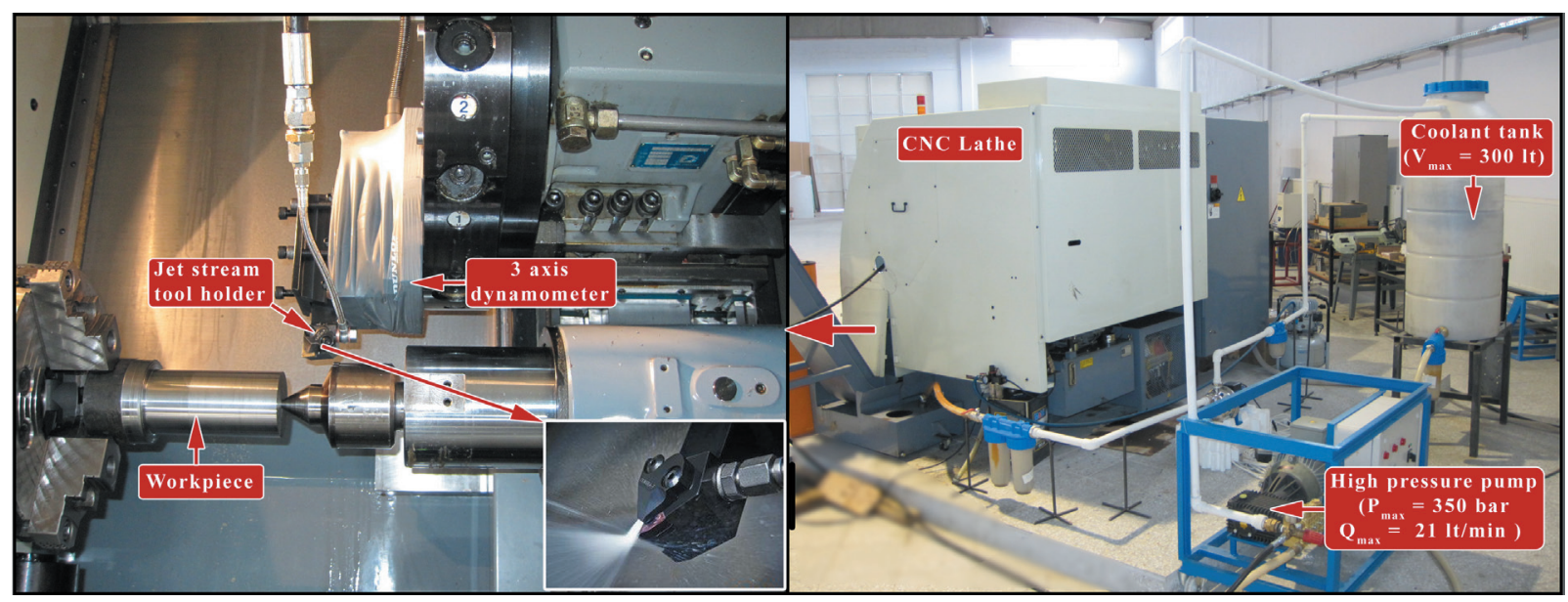

Fig. 1. Photographic view of experimental set-up and illustration of the high-pressure injection system

N, 0.14 to $0.23 \% \mathrm{O}, 0.01 \% \mathrm{H}, 0.3 \% \mathrm{Fe}, 50 \mathrm{ppm} \% \mathrm{Y}$, balance Ti. The mechanical properties of Ti6Al4V are tensile strength: 900 to $1160 \mathrm{MPa}$, yield strength: 830 MPa, elongation: 8\% [2].

\section{REGRESSION ANALYSIS}

In order to construct a hybrid model [14] for a singlepass straight-turning operations based on the multiple machining prformance measures, empirical equations have been obtained by multi-regression analysis of experimental responses shown in Table 2.

$F_{c}, F_{p}, F_{f}$ and $R_{a}$ were measured during the machining. The others $M_{R}, P_{c}$, were calculated based on cutting parameters and main cutting forces $\left(F_{c}\right)$, respectively and inserted as responses. The generated equations are presented in Eq. (1). with $R^{2}=0.99,1$ and 0.99 , respectively:

$$
\begin{gathered}
R_{a}=-0.42-0.002 V_{c}+10.31 f+0.0004 P, \\
M_{R}=6.5 \cdot 10^{-16} V_{c}+1.6 \cdot 10^{-13} f+2 V_{c} f,
\end{gathered}
$$

$P_{c}=-0.052+3.1 \cdot 10^{-3} V_{c}+0.31 f+5 \cdot 10^{-5} P+0.043 V_{c} f$.

\section{OPTIMIZATION CRITERION}

A hybrid model developed by Da et al. [14] was utilized for single-pass straight turning optimization problems. The parameters, $R_{a}, P_{c}$, and $M_{R}$ denote the surface roughness, cutting power and material removal rate, respectively. Corresponding constraints on these machining performance measures are assumed as, $R_{a}$ ', $P_{c}$ ' and $M_{R}$ '. The objective function can be constructed as seen in Eq. (2).

$$
\begin{aligned}
U_{\left(V_{c}, f\right)} & =C_{R}\left(\frac{R_{a}^{\prime}-R_{a}}{R_{a}^{\prime}}\right)+C_{P}\left(\frac{P_{c}^{\prime}-P_{c}}{P_{c}^{\prime}}\right)+ \\
& +C_{M}\left(\frac{M_{R}-M_{R}^{\prime}}{M_{R}^{\prime}}\right),
\end{aligned}
$$

where each term is normalized by using user-provided information concerning machining performance requirements. $C_{i}(i=R, P$ and $M)$ are weighting factors considered as the contribution coefficient of $i^{\text {th }}$ machining performance variable to the value of the operation. These weighting factors satisfy two conditions:

Table 2. The experiment results

\begin{tabular}{cccccccccc}
\hline No & $V_{c}[\mathrm{~m} / \mathrm{min}]$ & $f[\mathrm{~mm} / \mathrm{rev}]$ & $P[\mathrm{bar}]$ & $F_{c}[\mathrm{~N}]$ & $F_{p}[\mathrm{~N}]$ & $F_{f}[\mathrm{~N}]$ & $R_{a}[\mu \mathrm{m}]$ & $M_{R}[\mathrm{~cm} 3 / \mathrm{min}]$ & $P_{c}[\mathrm{~kW}]$ \\
\hline 1 & 50 & 0.1 & 6 & 424.1 & 95.3 & 95.9 & 0.45 & 10 & 0.35 \\
\hline 2 & 50 & 0.15 & 150 & 583.1 & 102.3 & 108.3 & 1.16 & 15 & 0.49 \\
\hline 3 & 50 & 0.2 & 300 & 740.8 & 121.5 & 119.7 & 1.66 & 20 & 0.62 \\
\hline 4 & 70 & 0.1 & 150 & 436.5 & 81.9 & 82.7 & 0.54 & 14 & 0.51 \\
\hline 5 & 70 & 0.15 & 300 & 605.8 & 111.1 & 110.8 & 1.06 & 21 & 0.71 \\
\hline 6 & 70 & 0.2 & 6 & 725.7 & 120.5 & 121.6 & 1.51 & 28 & 0.85 \\
\hline 7 & 90 & 0.1 & 300 & 445.3 & 91.8 & 92.6 & 0.58 & 18 & 0.67 \\
\hline 8 & 90 & 0.15 & 6 & 580.8 & 134.9 & 135.8 & 0.96 & 27 & 0.87 \\
\hline 9 & 90 & 0.2 & 150 & 720.5 & 122 & 121.5 & 1.49 & 36 & 1.08 \\
\hline
\end{tabular}




$$
\begin{gathered}
C_{R}+C_{P}+C_{M}=1, \\
0 \leq C_{i} \leq 1 \quad(i=R, P, M) .
\end{gathered}
$$

Corresponding constraints on these machining performance measures are assumed as $R_{a}{ }^{\prime}, P_{c}{ }^{\prime}$ and $M_{R}{ }^{\prime}$. Therefore, the constraint conditions are:

$$
\begin{gathered}
R_{a} \leq R_{a}^{\prime}, \quad P_{c} \leq P_{c}^{\prime}, \quad M_{R} \geq M_{R}^{\prime}, \\
V_{c \text { min }} \leq V_{c} \leq V_{c \text { max }}, \quad f_{\min } \leq f \leq f_{\text {max }} .
\end{gathered}
$$

Hence the optimization problem becomes:

$$
\begin{array}{cl}
\text { Maximize } & U_{\left(V_{c}, f\right)}, \\
\text { With respect to } & V_{c}, f, \\
\text { Subject to } & R_{a} \leq R_{a}^{\prime}, P_{c} \leq P_{c}^{\prime}, M_{R} \geq M_{R}^{\prime}, \\
& V_{c \min } \leq V_{c} \leq V_{c \max }, f_{\min } \leq f \leq f_{\max } .
\end{array}
$$

The material removal rate and cutting power have priority in the rough turning, because the main purpose is to remove the maximum material per unit of time in the rough turning. Thus, the weighting factors $C_{M}$ and $C_{P}$ are set equal to 0.45 and weighting factor for surface roughness, $C_{R}$, is made equal to 0.1 as the surface roughness is not given precedence in the rough turning. The weighting factors and constraints are shown in Table 3. The parameters used GA are also given in Table 4.

Table 3. Weighting factors and constraints for optimization

\begin{tabular}{lcc}
\hline Constraints & & Rough turning \\
\hline \multirow{2}{*}{ Weighting factors } & $C_{M}$ & 0.45 \\
\cline { 2 - 3 } & $C_{P}$ & 0.45 \\
\cline { 2 - 3 } & $C_{R}$ & 0.1 \\
\hline$V_{c}$ & {$[\mathrm{~m} / \mathrm{min}]$} & 50 to 90 \\
\hline$f$ & {$[\mathrm{~mm} / \mathrm{rev}]$} & 0.1 to 0.2 \\
\hline$a_{p}$ & {$[\mathrm{~mm}]$} & 2 \\
\hline$M_{R^{\prime}}$ & {$[\mathrm{cm} / \mathrm{min}]$} & 20 \\
\hline$P_{c}{ }^{\prime}$ & {$[\mathrm{kW}]$} & 0.7 \\
\hline$R_{a}{ }^{\prime}$ & & 1 \\
\hline
\end{tabular}

Table 4. Parameters used in GA

\begin{tabular}{ll}
\hline Population size & 300 \\
\hline Crossover fraction & 0.75 \\
\hline Max number of generations & 2000 \\
\hline
\end{tabular}

\section{RESULTS AND DISCUSSIONS}

\subsection{Optimization Results}

Figs. 2 to 4 show the contour plots with feasible regions and optimum points for conventional cooling
( $P=6$ bar $)$ and high pressure cooling $(P=150$ and $P=$ 300 bar) conditions, respectively. Feasible regions in HPJAC conditions are smaller than that in conventional cooling, as seen in Figs. 2 to 4, which is due to the increasing effect of HPJAC on surface roughness. Surface quality is reduced with rising pressure levels, which also could be shown in optimization results for each pressure level given in Tables 5 to 7 . This observation confirms the experiments of Courbon et al. [10], who stated that this may result from the fact that the chips damage the machined surface with high pressure when the velocity of the chip is relatively low. Similar observations have been also reported in [1]. In contrast, there is no significant difference in the optimization results, $P c$, which were calculated based on the main cutting force for each pressure level. It can be assumed that HPJAC has not considerably affected the main cutting forces in this set of experiments. Optimum cutting parameters are also quite similar, especially at $P=6$ and 150 bar cooling conditions; the responses $\left(P_{c}, M_{R}\right)$, are almost same. However, as discussed in the next section, tool life is remarkably improved by HPJAC.

\subsection{Tool Wear Test Results}

After the optimization of machining performance, tool wear tests were conducted at constant cutting parameters, which are close to the optimum point for each pressure level, $V_{c}=70 \mathrm{~m} / \mathrm{min}, f=0.15$ $\mathrm{mm} / \mathrm{rev}, a_{p}=2 \mathrm{~mm}$, under conventional and highpressure cooling conditions. Tool wear limits were considered to be average tool flank wear, $V B B=0.3$ mm, maximum tool flank wear, $V B B_{\max }=0.6 \mathrm{~mm}$, and notch wear, $V B N=1 \mathrm{~mm}$, according to ISO 3685:1993 standards [24].

Tool life for conventional and high-pressure cooling conditions are shown in Fig. 5. It can be clearly seen that high pressure cooling conditions have an increasing effect on tool life compared to conventional cooling, which is in agreement with the experiments performed by Nandy et al. [1], Ezugwu et al. [2] and Palanisamy et al. [7]. Hong et al. [19] stated that titanium and its alloys are poor thermal conductors. As a result, the heat generated when machining titanium cannot dissipate quickly; rather, most of the heat is concentrated on the cutting edge and tool face, which causes rapid tool wear. The injection of high pressure coolant to the tool-chip interface provides efficient lubrication and cooling by penetrating the cutting zone, which results in a considerable reduction in the temperature. Hence, 


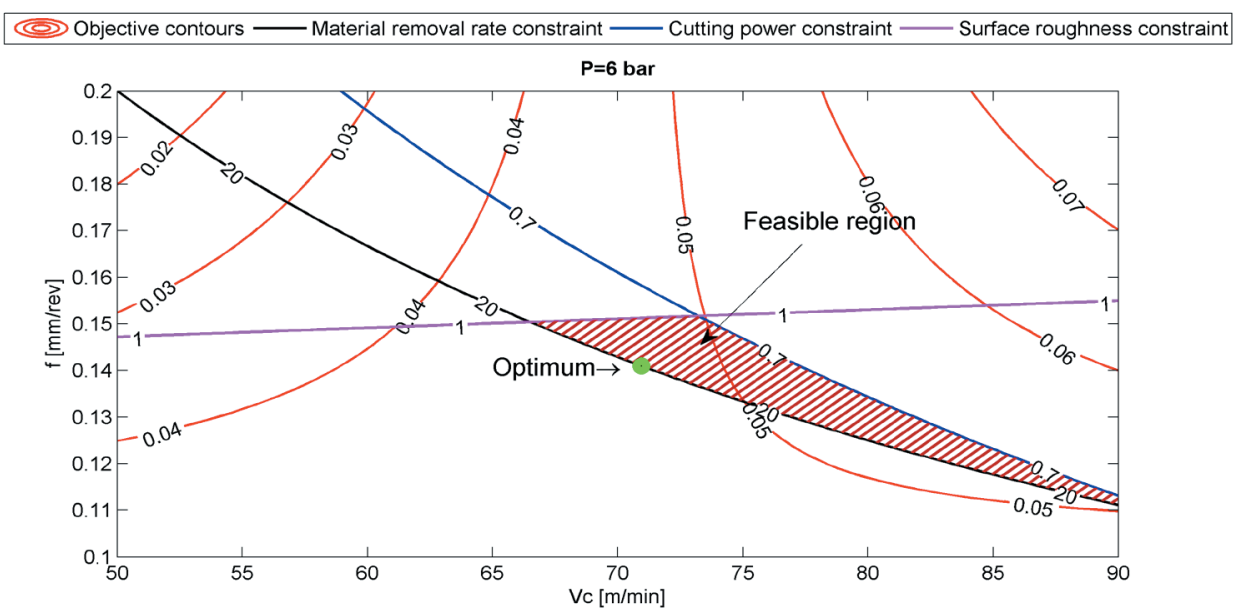

Fig. 2. Illustration of feasible region and optimum point for conventional cooling ( $P=6$ bar)

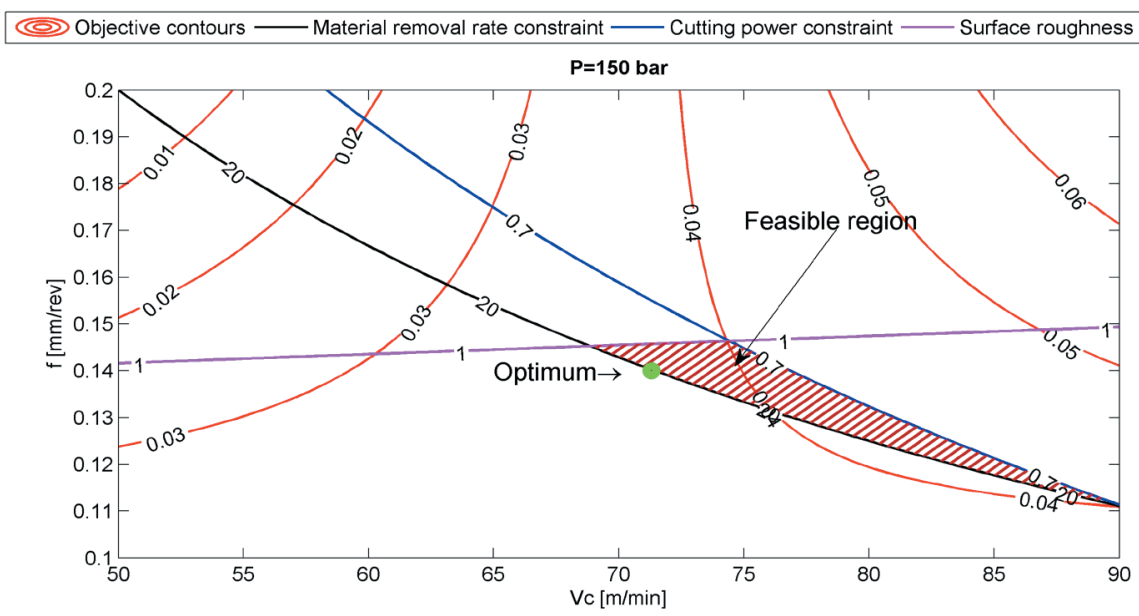

Fig. 3. Illustration of feasible region and optimum point for high pressure cooling ( $P=150$ bar)

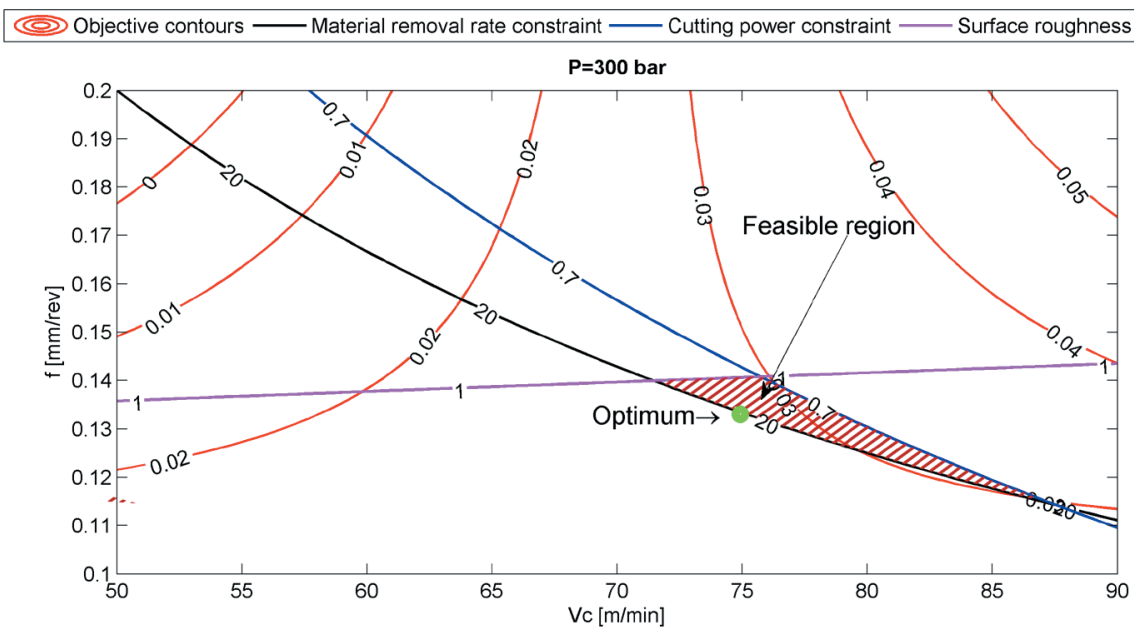

Fig. 4. Illustration of feasible region and optimum point for high pressure cooling ( $P=300$ bar $)$

cutting tool wear caused by high temperatures could be reduced or entirely prevented, leading to extended tool life in comparison to conventional cooling. This conclusion has also been stated in [20] to [22]. 


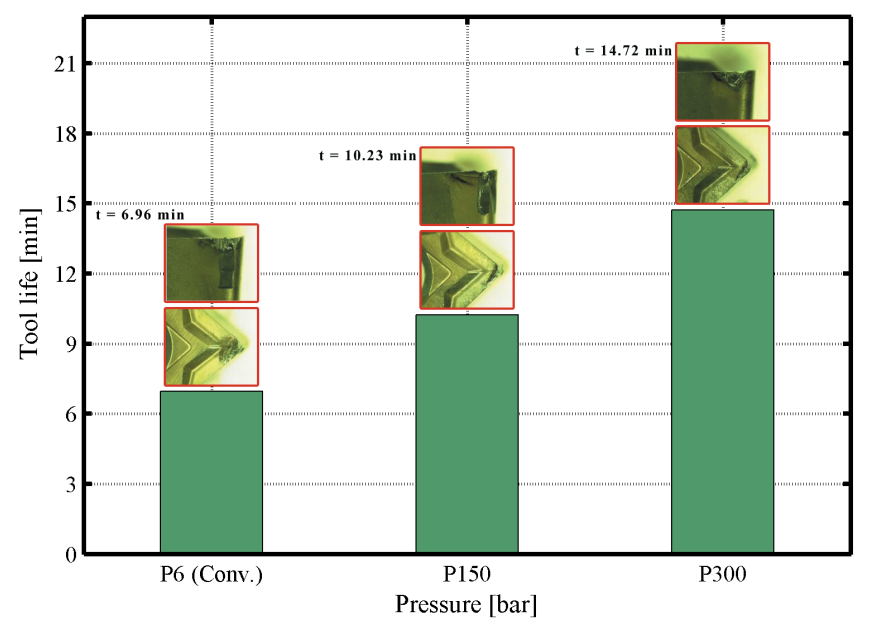

Fig. 5. Tool life for conventional and high pressure cooling conditions at $V_{c}=70 \mathrm{~m} / \mathrm{min}, f=0.15 \mathrm{~mm} / \mathrm{rev}, a_{p}=2 \mathrm{~mm}$

Table 5. Optimization results for conventional cooling $(P=6$ bar $)$

\begin{tabular}{cccccc}
\hline $\begin{array}{c}V_{c} \\
{[\mathrm{~m} / \mathrm{min}]}\end{array}$ & $\begin{array}{c}f \\
{[\mathrm{~mm} / \mathrm{rev}]}\end{array}$ & $\begin{array}{c}a_{p} \\
{[\mathrm{~mm}]}\end{array}$ & $\begin{array}{c}R_{a} \\
{[\mu \mathrm{m}]}\end{array}$ & $\begin{array}{c}P_{c} \\
{[\mathrm{~kW}]}\end{array}$ & $\begin{array}{c}M_{R} \\
{[\mathrm{~cm} 3 / \mathrm{min}]}\end{array}$ \\
\hline 71 & 0.141 & 2 & 0.89 & 0.64 & 20 \\
\hline
\end{tabular}

Table 6. Optimization results for high pressure cooling ( $P=150$ bar)

\begin{tabular}{cccccc}
\hline $\begin{array}{c}V_{c} \\
{[\mathrm{~m} / \mathrm{min}]}\end{array}$ & $\begin{array}{c}f \\
{[\mathrm{~mm} / \mathrm{rev}]}\end{array}$ & $\begin{array}{c}a_{p} \\
{[\mathrm{~mm}]}\end{array}$ & $\begin{array}{c}R_{a} \\
{[\mu \mathrm{m}]}\end{array}$ & $\begin{array}{c}P_{c} \\
{[\mathrm{~kW}]}\end{array}$ & $\begin{array}{c}M_{R} \\
{\left[\mathrm{~cm}^{3} / \mathrm{min}\right]}\end{array}$ \\
\hline 71.3 & 0.14 & 2 & 0.94 & 0.65 & 20 \\
\hline
\end{tabular}

Table 7. Optimization results for high pressure cooling ( $P=300$ bar)

\begin{tabular}{cccccc}
\hline $\begin{array}{c}V_{c} \\
{[\mathrm{~m} / \mathrm{min}]}\end{array}$ & $\begin{array}{c}f \\
{[\mathrm{~mm} / \mathrm{rev}]}\end{array}$ & $\begin{array}{c}a_{p} \\
{[\mathrm{~mm}]}\end{array}$ & $\begin{array}{c}R_{a} \\
{[\mu \mathrm{m}]}\end{array}$ & $\begin{array}{c}P_{c} \\
{[\mathrm{~kW}]}\end{array}$ & $\begin{array}{c}M_{R} \\
{[\mathrm{~cm} 3 / \mathrm{min}]}\end{array}$ \\
\hline 75 & 0.133 & 2 & 0.92 & 0.66 & 20 \\
\hline
\end{tabular}

\section{CONCLUSIONS}

In this study, machining performance optimization was experimentally investigated in the turning of Ti6Al4V under HPJAC and conventional cooling conditions. Therefore, a number of machining tests with Ti6Al4V were carried out in conventional and various high-pressure levels of cooling conditions. By means of multi-regression analysis, empirical equations were obtained, and objective functions for optimization were constructed using these equations based on the hybrid model. Furthermore, tool wear tests were carried out for each cooling condition at constant machining parameters.

The following conclusions can be drawn from this work:

1. The hybrid model used in this research for the optimization of machining performance is very useful for determining optimum cutting parameters according to the given optimization criteria.

2. Feasible regions in HPJAC conditions are smaller than that in conventional cooling, because of the increasing effect of HPJAC on surface roughness.

3. There are no significant change optimization results, Pc, in all the cooling conditions. This is due to the fact that high pressure cooling has not considerably influenced the main cutting forces in this set of experiment.

4. Although the optimum cutting parameters and its responses are quite similar, tool life is remarkably different in each cooling condition. Tool life is about $47 \%$ and $112 \%$ higher than conventional cooling in $\mathrm{P}=150$ and 300 bar, respectively.

5. The application of high pressure cooling during the machining of hard-to-cut materials supports sustainability in manufacturing by increasing tool life, thus resulting in lower machining cost.

\section{ACKNOWLEDGEMENTS}

This study was supported by the Scientific and Technological Research Council of Turkey (TÜBITAK) and the Slovenian Research Agency (ARRS). The authors also would like to thank the companies SECOTOOLS, BLASER SwissLube and TAI-TUSAŞ A.Ş. for their support to this study.

\section{REFERENCES}

[1] Nandy, A.K., Gowrishankar, M.C., Paul, S. (2009). Some studies on high-pressure cooling in turning of Ti-6Al-4V. International Journal of Machine Tools \& Manufacture, vol. 49, no. 2, p. 182-198, DOI:10.1016/j. ijmachtools.2008.08.008. 
[2] Ezugwu, E.O., Bonney, J., Da Silva, R.B., Machado A.R., Ugwoha, E. (2009). High productivity rough turning of Ti-6Al-4V alloy, with flood and high-pressure cooling. Society of Tribologists and Lubrication Engineers, Tribology Transactions, vol. 52, no. 3 p. 95400, DOI:10.1080/10402000802687866.

[3] Machai, C., Biermann, D. (2011). Machining of $\beta$-titanium-alloy $\mathrm{Ti}-10 \mathrm{~V}-2 \mathrm{Fe}-3 \mathrm{Al}$ under cryogenic conditions: Cooling with carbon dioxide snow. Journal of Materials Processing Technology, vol. 211, no. 6, p. 1175-1183, DOI:10.1016/j.jmatprotec.2011.01.022.

[4] Hong, S.Y., Ding, Y. (2001). Cooling approaches and cutting temperatures in cryogenic machining of Ti-6Al-4V. International Journal of Machine Tools \& Manufacture, vol. 41, no. 10, p. 1417-1437, DOI:10.1016/S0890-6955(01)00026-8.

[5] Sharma, V.S., Dogra, M., Suri, N.M. (2009). Cooling techniques for improved productivity in turning. International Journal of Machine Tools \& Manufacture, vol. 49, no. 6, p. 435-453, DOI:10.1016/j. ijmachtools.2008.12.010.

[6] Çolak, O. (2012). Investigation on Machining Performance of Inconel 718 under High Pressure Cooling Conditions. Strojniški vestnik - Journal of Mechanical Engineering, vol. 58, no. 11, p. 683-690, DOI:10.5545/sv-jme.2012.730.

[7] Palanisamy, S., McDonald, S.D., Dargusch, M.S. (2009). Effects of coolant pressure on chip formation while turning Ti6A14V alloy. International Journal of Machine Tools \& Manufacture, vol. 49, no. 9, p. 739743, DOI:10.1016/j.ijmachtools.2009.02.010.

[8] Ezugwu, E.O., Bonney, J. (2004). Effect of highpressure coolant supply when machining nickel-base, Inconel 718, alloy with coated carbide tools. Journal of Materials Processing Technology, vol. 153-154, p. 1045-1050, DOI:10.1016/j.jmatprotec.2004.04.329.

[9] Ezugwu, E.O., Bonney, J., Silva, R.B.D., Çakir, O. (2007). Surface integrity of finished turned Ti-6Al$4 \mathrm{~V}$ alloy with PCD tools using conventional and high pressure coolant supplies. International Journal of Machine Tools \& Manufacture, vol. 47, no. 6, p. 884891, DOI:10.1016/j.ijmachtools.2006.08.005.

[10] Courbon, C., Kramar, D., Krajnik, P., Pusavec, F., Rech, J., Kopac, J. (2009). Investigation of machining performance in high-pressure jet assisted turning of Inconel 718: an experimental study. International Journal of Machine Tools \& Manufacture, vol. 49, no. 14, p. 1114-1125, DOI:10.1016/j. ijmachtools.2009.07.010.

[11] Venkata, R.R., Kalyankar, V.D. (2012). Parameter optimization of modern machining processes using teaching-learning-based optimization algorithm. Engineering Applications of Artificial Intelligence, vol. 26, no. 1, p. 524-531, DOI:10.1016/j. engappai.2012.06.007.

[12] Cus, F., Balic, J. (2003). Optimization of cutting process by GA approach. Robotics and Computer
Integrated Manufacturing, vol. 19, no. 1-2, p. 113-121, DOI:10.1016/S0736-5845(02)00068-6.

[13] Raja, S.B, Baskar, N. (2012). Application of Particle Swarm Optimization technique for achieving desired milled surface roughness in minimum machining time. Expert Systems with Applications, vol. 39, no. 5, p. 5982-5989, DOI:10.1016/j.eswa.2011.11.110.

[14] Da, Z.J., Sabler, J.P., Jawahir, I.S. (1996). Multiple criteria optimization of finish turning operations based on a hybrid model. Proceedings of the ASME Design Engineering Technical Conferences and Computers in Engineering Conference, Irvine.

[15] Hagiwara, M., Chen, S., Jawahir, I.S. (2009). Contour finish turning operations with coated grooved tools: Optimization of machining performance. Journal of Materials Processing Technology, vol. 209, no. 1, p. 332-342, DOI:10.1016/j.jmatprotec.2008.02.023.

[16] Jawahir, I.S., Wang, X. (2007). Development of hybrid predictive models and optimization techniques for machining operations. Journal of Materials Processing Technology, vol. 185, no. 1-3, p. 46-59, DOI:10.1016/j. jmatprotec.2006.03.133.

[17] Wang, X., Da, Z.J., Balaji, A.K., Jawahir, I.S. (2007). Performance-based predictive models and optimization methods for turning operations and applications: Part 3 - optimum cutting conditions and selection of cutting tools. Journal of Manufacturing Processes, vol. 9, no. 1 p. 61-74, DOI:10.1016/S1526-6125(07)70108-1.

[18] Kardekar, A.D. (2005). Modeling and Optimization of Machining Performance Measures in Face Milling of Automotive Aluminum Alloy A380 under Different Lubrication/Cooling Conditions for Sustainable Manufacturing, M.Sc. Thesis, University of Kentucky, Lexington.

[19] Hong, S.Y., Markus, I., Jeong, W. (2001). New cooling approach and tool life improvement in cryogenic machining of titanium alloy Ti-6Al-4V. International Journal of Machine Tools \& Manufacture, vol. 41, no. 15. p. 2245-2260, DOI:10.1016/S0890-6955(01)00041-4.

[20] Kaminski, J., Alvelid, B. (2000). Temperature reduction in the cutting zone in water-jet assisted turning. Journal of Materials Processing Technology, vol. 106, no. 1-3, p. 68-73, DOI:10.1016/S0924-0136(00)00640-3.

[21] Dahlman, P., Escursell, M. (2004). High-pressure jetassisted cooling: a new possibility for near net shape turning of decarburized steel. International Journal of Machine Tools \& Manufacture, vol. 44, no. 1, p. 109115, DOI:10.1016/S0890-6955(03)00058-0.

[22] Kramar, D., Krajnik, P., Kopac, J. (2010). Capability of high pressure cooling in the turning of surface hardened piston rods. Journal of Materials Processing Technology, vol. 210, no. 2, p. 212-218, DOI:10.1016/j. jmatprotec.2009.09.002.

[23] Yang, K., El-Haik, B. (2003). Design for Six Sigma. The McGraw-Hill, New York.

[24] ISO 3685:1993 (1993). Tool-life testing with singlepoint turning tools. International Organization for Standardization, Geneva. 